\title{
PENGOLAHAN LIMBAH PRODUKSI RADIOISOTOP MENGGUNAKAN RESIN PENUKAR ANION
}

\author{
AISYAH, HERLAN MARTONO, WATI \\ Pusat Teknologi Limbah Radioaktif \\ Kawasan Puspiptek Serpong, Tangerang 15310
}

\begin{abstract}
Abstrak
PENGOLAHAN LIMBAH PRODUKSI RADIOISOTOP MENGGUNAKAN

RESIN PENUKAR ANION. Dalam produksi radioisotop ${ }^{99}$ Mo akan ditimbulkan limbah radioaktif yang mengandung campuran uranium dan hasil belah. Pengolahan dilakukan untuk memisahkan uranium dari hasil belah menggunakan resin penukar anion. Resin penukar anion akan selektif mengikat uranium dalam bentuk uranium kompleks. Telah dilakukan penelitian pengolahan limbah simulasi dengan konsentrasi uranium $0,05 \mathrm{~g} / \mathrm{L}$ menggunakan resin penukar anion amberlit IRA$400(\mathrm{Cl})$ dengan cara mengkomplekkan uranium dengan $\mathrm{Na}_{2} \mathrm{CO}_{3}$. Variable yang dipelajari adalah jumlah $\mathrm{Na}_{2} \mathrm{CO}_{3}$ dan waktu kontak. Penjerapan uranium yang optimal diperoleh pada penambahan $\mathrm{Na}_{2} \mathrm{CO}_{3}$. 0,75 gram ( $\mathrm{U} / \mathrm{Na}_{2} \mathrm{CO}_{3} \approx 0,067$ ), waktu kontak 60 menit dengan penjerapan uranium 88,6\% berat. Resin IRA-400 (Cl) yang jenuh uranium disolidifikasi dengan polimer resin epoksi. Karakterisasi polimer-limbah hasil solidifikasi dilakukan dengan pengukuran densitas, kuat tekan dan laju pelindihan. Densitas ditentukan dengan mengukur berat dan volume polimer-limbah, kuat tekan ditentukan dengan alat uji tekan Paul Weber dan laju pelindihan ditentukan dengan alat sokhlet. Hasil pengukuran menunjukkan bahwa kandungan limbah yang optimal adalah $20 \%$ berat dengan densitas $1,036 \mathrm{~g} / \mathrm{cm}^{3}$, kuat tekan $12,153 \mathrm{kN} / \mathrm{cm}^{2}$ dan tidak terdeteksi adanya pelindihan uranium keluar dari polimer-limbah.
\end{abstract}

Kata kunci: Limbah uranium, resin penukar anion, solidifikasi

\begin{abstract}
TREATMENT OF RADIOISOTOPE PRODUCTION WASTE BY USING ANION EXCHANGE RESIN. Production of radioisotope ${ }^{99}$ Mo would cause radioactive waste containing a mixture of uranium and fission products. The treatment separates the uranium from the fission products by using anion exchange resin. Anion resin would selectively bind the uranium in the form of complex uranium. A simulation study of waste treatment with the uranium concentration of $0.05 \mathrm{~g} / \mathrm{L}$ has been carried out using anion exchange resin amberlite IRA-400Cl by complexing the uranium with $\mathrm{Na}_{2} \mathrm{CO}_{3}$. The parameters which were studied are the amount of $\mathrm{Na}_{2} \mathrm{CO}_{3}$ and contact time. The optimal sorption of uranium obtained in the addition of $\mathrm{Na}_{2} \mathrm{CO}_{3} .0 .75$ gram $\left(\mathrm{U} / \mathrm{Na}_{2} \mathrm{CO}_{3} \approx 0.067\right), 60$ minute contact time with the uranium sorption of $88.6 \%$. weight. The IRA- $400(\mathrm{Cl})$ resin that contains uranium was solidified with epoxy resin polymer. Characterization of the solidified polymerwaste was determined with measurements of density, compressive strength, and leaching rate. The density was determined by measuring its weight and volume polymer-waste, the compressive strength was measured with Paul Weber compactor and the leaching rates was determined by soxhlet apparatus. The results of measurements showed that the optimum waste content is $20 \%$ weight, the density is
\end{abstract}


$1.036 \mathrm{~g} / \mathrm{cm}^{3}$, the compressive strength is $12.153 \mathrm{kN} / \mathrm{cm}^{2}$, and leaching of uranium out from the polymer-waste was not detected.

Keywords: Uranium waste, anion exchange resin, solidification

\section{PENDAHULUAN}

Pemanfaatan teknologi nuklir di bidang kedokteran telah memberikan peran yang cukup besar dalam pencitraan (imaging) organ tubuh manusia. Radioisotop teknesium- $99 \mathrm{~m}\left({ }^{99 \mathrm{~m}} \mathrm{Tc}\right)$ dipakai hampir $80 \%$ di bidang pencitraan nuklir yaitu untuk pencitraan jantung, otak, ginjal, hati, dan tulang untuk menemukan kelainan-kelainan yang ada didalamnya. Hal ini didasarkan atas sifat ${ }^{99 \mathrm{~m}} \mathrm{Tc}$ yang memiliki waktu paro pendek hanya 6 jam, hanya memancarkan radiasi gamma dengan energi rendah sebesar $140 \mathrm{keV}$, tidak memancarkan partikel bermuatan, dan dapat diperoleh dalam bentuk bebas pengemban dari radioisotop Molybdenum- $99\left({ }^{99} \mathrm{Mo}\right)$ serta dapat membentuk ikatan dengan senyawa-senyawa organik. Oleh karena itu penggunaan radioisotop ini memiliki dampak radiasi yang kecil bagi tubuh ${ }^{[1]}$.

Radioisotop ${ }^{99 \mathrm{~m}} \mathrm{Tc}$ diperoleh dari induk ${ }^{99} \mathrm{Mo}$. Proses produksi ${ }^{99} \mathrm{Mo} \mathrm{di}$ PT. Batan Teknologi mirip dengan yang dilakukan di Canada yaitu dengan target $\mathrm{U}_{3} \mathrm{O}_{8}$ dalam bentuk serbuk yang dilarutkan dalam $\mathrm{HNO}_{3}$ pekat dengan pengkayaan uranium $92,3 \%$ yang diiradiasi dalam reaktor GA Siwabessy selama 96 jam pada daya reaktor $15 \mathrm{MW}$. Proses pengambilan ${ }^{99} \mathrm{Mo}$ dilakukan setelah target dikeluarkan dari reaktor dan didinginkan selama 6 jam ${ }^{[2,3,4]}$. Dalam proses pengambilan ${ }^{99}$ Mo dari target akan ditimbulkan limbah radioaktif yang mengandung campuran ${ }^{235} \mathrm{U}$ sisa yang tidak terbakar, ${ }^{238} \mathrm{U}$,dan radionuklida hasil belah. Limbah ini memerlukan ekstraksi bertingkat untuk memisahkan antara uranium dan hasil belah. Salah satu hasil ekstraksi berupa rafinat yang mengandung hasil belah dan sedikit uranium ${ }^{[5]}$. Limbah rafinat yang mengandung uranium ini memiliki toksisitas yang tinggi dan berumur panjang sehingga memerlukan pengolahan yang tepat agar tidak memiliki potensi dampak radiologis bagi manusia dan lingkungan.

Prinsip pengolahan limbah rafinat dari produksi radioisotop ini adalah memisahkan uranium dari hasil belah. Hal ini dilakukan karena pengelolaan limbah uranium akan berbeda dengan hasil belah. Radionuklida uranium yang berumur panjang memerlukan solidifikasi dengan polimer dan disimpan lestari dalam formasi geologi. Sementara itu radionuklida hasil belah jika aktifitasnya tidak terlalu besar dibiarkan meluruh sehingga menjadi limbah aktifitas rendah/sedang dan disolidifikasi dengan semen lalu disimpan lestari pada penyimpanan tanah dangkal. Untuk hasil belah yang aktifitasnya sangat 
tinggi seperti pada limbah hasil olah ulang, solidifikasi dilakukan dengan gelas dan penyimpanan lestari dilakukan pada formasi geologi ${ }^{[6]}$.

Untuk memisahkan uranium dari hasil belah digunakan resin penukar anion ${ }^{[7]}$. Resin penukar anion yang digunakan dalam penelitian ini adalah amberlit IRA-400 (Cl). Resin ini merupakan kopolimerisasi dari styrene dan divinyl benzene yang mengandung gugus fungsional ammonium basa kuarterner $\mathrm{R}_{4} \mathrm{~N}^{+} \mathrm{Cl}^{-}$, dengan $\mathrm{R}$ adalah radikal organik $\left(-\mathrm{CH}_{3}\right)$ dan $\mathrm{Cl}^{-}$ merupakan ion aktif untuk pertukaran dengan anion lain. Rumus molekulnya adalah $\mathrm{C}_{22} \mathrm{H}_{28} \mathrm{ClN}$ dengan struktur molekul seperti yang disajikan pada Gambar $1^{[8,9]}$.

Resin penukar anion dapat menyerap uranium dalam bentuk kompleks, sehingga limbah uranium harus dikomplekkan terlebih dahulu.

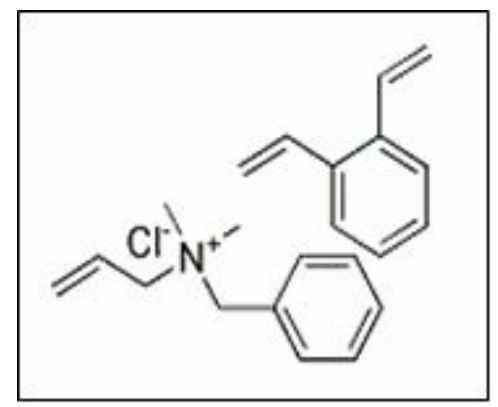

Gambar 1. Struktur molekul IRA-400 (CL) ${ }^{[8,9]}$

Dalam penelitian ini uranium dikomplekkan dengan natrium karbonat $\left(\mathrm{Na}_{2} \mathrm{CO}_{3}\right)$ dan akan terbentuk ion $\left[\mathrm{UO}_{2}\left(\mathrm{CO}_{3}\right)_{3}\right]^{-4}$. Resin penukar anion akan selektif menangkap ion $\left.\mathrm{UO}_{2}\left(\mathrm{CO}_{3}\right)_{3}\right]^{-4}$ dan hasil belah akan lolos, sehingga uranium akan terpisah dari hasil belah dengan Persamaan reaksi 1 berikut:

$$
\mathrm{UO}_{2}^{+2}+3 \mathrm{CO}_{3}^{-2} \leftrightarrow\left[\mathrm{UO}_{2}\left(\mathrm{CO}_{3}\right)_{3}\right]^{-4}
$$

Pada pembentukan kompleks perlu ditentukan banyaknya $\mathrm{Na}_{2} \mathrm{CO}_{3}$ supaya kompleks yang terbentuk cukup banyak sehingga uranium yang terserap juga banyak. Jika pengkompleks yang ditambahkan terlalu banyak maka larutan mengandung $\mathrm{CO}_{3}^{-2}$ bebas dan akan diserap resin sehingga kapasitas resin untuk menyerap uranium menjadi berkurang ${ }^{[10]}$.

Proses pertukaran ion meliputi penjerapan ion-ion kompleks secara selektif dan kuantitatif oleh resin penukar anion dengan Persamaan reaksi 2 sebagai berikut ${ }^{[10]}$ :

$$
4 \mathrm{R}_{4} \mathrm{~N}^{+} \mathrm{Cl}^{-}+\left[\mathrm{UO}_{2}\left(\mathrm{CO}_{3}\right)_{3}\right]^{-4} \leftrightarrow\left(\mathrm{R}_{4} \mathrm{~N}^{+}\right)_{4}\left[\mathrm{UO}_{2}\left(\mathrm{CO}_{3}\right)_{3}\right]^{-4}+4 \mathrm{Cl}^{-}
$$


Selanjutnya resin penukar anion yang telah jenuh dengan uranium disolidifikasi dengan bahan matriks tertentu hingga uranium aman terkungkung di dalamnya ${ }^{[11]}$.

Uranium termasuk radionuklida berumur panjang, sehingga polimer merupakan bahan matriks yang cocok untuk solidifikasinya. Resin epoksi dengan merek dagang EPOSIR 7120 dipilih sebagai bahan solidifikasi karena memiliki sifat yang unggul, diantaranya sifat mekanik yang baik, tahan terhadap bahan kimia, adesif, dan mudah diproses. Polimer ini terbentuk dari reaksi antara epiklorohidrin dengan bifenil propana (Bisfenol A), seperti yang disajikan pada Gambar $2^{[9,12]}$.<smiles>CC(C)(c1ccc([NH3+])cc1)c1ccc(O)cc1</smiles>

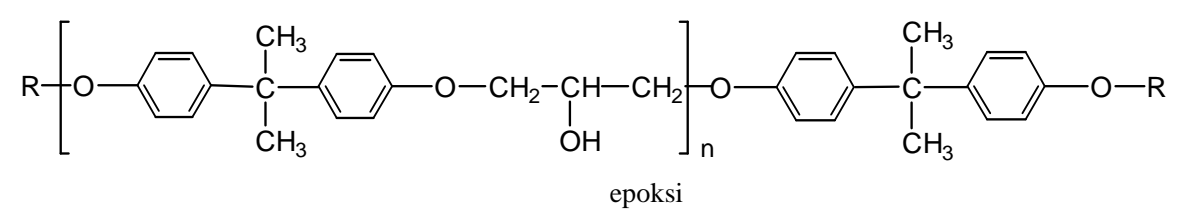

Gambar 2. Pembentukan Epoksi Oleh Reaksi Bisfenol A dan Epiklorohidrin $^{[9,12]}$

Hasil solidifikasi berupa polimer-limbah (campuran resin IRA-400 (Cl) jenuh uranium, polimer resin epoksi dan hardener) di tentukan karakteristiknya yaitu densitas, kuat tekan, dan laju pelindihannya. Karakteristik ini diperlukan guna menjamin bahwa hasil pengolahan limbah telah memenuhi standar keselamatan. Densitas diperlukan untuk perancangan sistem transportasi dan penyimpanan limbah, kuat tekan diperlukan guna mengetahui kekuatan polimer-limbah bila jatuh atau menerima beban tumpuk pada tempat penyimpanan, sedangkan laju pelindihan diperlukan guna mengetahui kualitas polimer-limbah dalam mengungkung radionuklida agar tidak terlindih keluar ${ }^{[13,14,15,16]}$.

Dalam penelitian ini digunakan limbah simulasi yang mengandung uranium dengan konsentrasi $0,05 \mathrm{~g} / \mathrm{L}$. Penentuan konsentrasi uranium dilakukan dengan metode spektrofotometri UV-VIS menggunakan pengompleks arsenazo III. Percobaan penjerapan uranium oleh resin amberlit IRA-400 (Cl) dilakukan menggunakan pengkompleks $\mathrm{Na}_{2} \mathrm{CO}_{3}$ dengan parameter jumlah $\mathrm{Na}_{2} \mathrm{CO}_{3}$ dan waktu kontak. Resin amberlit IRA-400 $(\mathrm{Cl})$ 
yang telah jenuh uranium disolidifikasi dengan polimer resin epoksi. Karakteristik polimer-limbah yang dipelajari adalah pengaruh kandungan limbah terhadap densitas, kuat tekan, dan laju pelindihan. Penentuan densitas dilakukan dengan mengukur volume dan berat polimer-limbah, sedangkan kuat tekan ditentukan dengan alat uji tekan PAUL WEBER. Laju pelindihan ditentukan dengan metode uji pelindihan dipercepat menggunakan alat soklet dengan media pelindih air pada suhu $100^{\circ} \mathrm{C}$.

\section{TATA KERJA}

\section{Bahan}

Dalam penelitian ini digunakan bahan : Uranil nitrat heksahidrat $\left\{\mathrm{UO}_{2}\left(\mathrm{NO}_{3}\right)_{2} \cdot 6 \mathrm{H}_{2} \mathrm{O}\right\}$, natrium karbonat $\left(\mathrm{Na}_{2} \mathrm{CO}_{3}\right)$ sebagai pengkompleks, resin penukar anion jenis amberlit IRA-400 Cl, arsenazo III, larutan $\mathrm{NaOH}$ dan $\mathrm{HCl}$, dan polimer (resin epoksi) EPOSIR 7120

\section{Peralatan}

Dalam penelitian ini digunakan beberapa alat, diantaranya alat pengocok (roller), alat analisis kadar uranium UV-VIS, alat uji tekan Paul Weber, alat uji lindih soxhlet, cetakan polimer.

\section{Cara Kerja}

Penjerapan Uranium oleh Resin Amberlit IRA-400 (Cl)

Limbah produksi radioisotop simulasi dibuat dengan cara melarutkan $\left\{\mathrm{UO}_{2}\left(\mathrm{NO}_{3}\right)_{2} \cdot 6 \mathrm{H}_{2} \mathrm{O}\right\}$ dalam air bebas mineral sehingga diperoleh konsentrasi uranium $0,05 \mathrm{~g} / \mathrm{L}$.

Percobaan penentuan jumlah pengkompleks $\mathrm{Na}_{2} \mathrm{CO}_{3}$ dilakukan dengan cara mencampur $250 \mathrm{~mL}$ larutan limbah simulasi, $250 \mathrm{ml}$ air bebas mineral dan 0,$25 ; 0,5 ; 0,75 ; 1 ; 1,25 ; 1,5 ; 2 ;$ dan 2,5 gram pengkompleks $\mathrm{Na}_{2} \mathrm{CO}_{3}$. Kemudian kedalam campuran ditambahkan 0,25 gram resin amberlit IRA$400(\mathrm{Cl})$ dan dikocok selama 1 jam. Dari masing-masing sampel dianalisis kadar uranium dalam beningannya dengan metode spektrofotometri UV-VIS menggunakan pengompleks arsenazo III. Penjerapan uranium yang optimal merupakan jumlah pengkompleks $\mathrm{Na} 2 \mathrm{CO} 3$ yang terbaik dan digunakan dalam percobaan selanjutnya.

Percobaan dengan parameter waktu kontak dilakukan dengan cara mencampur $250 \mathrm{ml}$ larutan limbah simulasi, 0,25 gram resin amberlit IRA$400(\mathrm{Cl})$, pengkompleks $\mathrm{Na}_{2} \mathrm{CO}_{3}$ dengan jumlah terbaik dan $250 \mathrm{ml}$ air. Campuran di rolling dengan waktu kontak 10,20,30,40,50,60,70, dan 80 menit. Dari masing-masing sampel dianalisis kadar uranium dalam 
beningannya dengan metode spektrofotometri UV-VIS menggunakan pengompleks arsenazo III. Penjerapan uranium yang optimal merupakan waktu kontak terbaik.

Solidifikasi Resin Amberlit IRA-400 (Cl) Jenuh Uranium

Solidifikasi resin Amberlit IRA-400 (Cl) jenuh uranium menggunakan polimer resin epoksi dilakukan dengan parameter kandungan limbah. Percobaan dilakukan dengan cara mencampur polimer, hardener dengan resin Amberlit IRA-400 $(\mathrm{Cl})$ jenuh uranium dengan kandungan limbah 0, 10, 20, 30, 40, dan $50 \%$ berat. Campuran diaduk sampai homogen dan dicetak dalam cetakan silindris dengan diametr $25 \mathrm{~mm}$ dan tinggi $20 \mathrm{~mm}$ dan dibiarkan mengeras dengan waktu curing $8-12$ jam. Polimer-limbah (campuran resin epoksi, hardener dan resin Amberlit IRA-400 (Cl) jenuh uranium) yang telah mengeras selanjutnya dilakukan pengujian karakteristiknya.

Karakterisasi Polimer-Limbah Hasil Solidifikasi ${ }^{[13,14,15,16]}$

Karakteristik polimer-limbah hasil solidifikasi yang diuji adalah densitas, kuat tekan dan laju pelindihan. Densitas polimer-limbah ditentukan dengan menimbang dan mengukur volume berdasarkan diameter dan tinggi polimerlimbah yang berbentuk silinder kemudian dihitung dengan Persamaan 3:

$$
\rho=\frac{m}{V}
$$

Dengan :

$\rho=\operatorname{densitas}\left(\mathrm{g} / \mathrm{cm}^{3}\right)$

$\mathrm{m}=$ massa polimer-limbah $(\mathrm{g})$

$\mathrm{v}=$ volume polimer-limbah $\left(\mathrm{cm}^{3}\right)$.

Kuat tekan polimer-limbah ditentukan menggunakan alat uji tekan Paul Weber dengan cara menekan polimer limbah yang berbentuk silindris sampai retak/pecah, kemudian dihitung dengan Persamaan 4: .

$$
\sigma_{c}=\frac{P_{m a k s}}{A}
$$

dengan :

$\sigma_{r}=$ kuat tekan $\left(\mathrm{kN} / \mathrm{cm}^{2}\right)$

$\mathrm{P}_{\text {maks }}=$ beban tekanan maksimum $(\mathrm{kN})$

A $=$ luas penampang $\left(\mathrm{cm}^{2}\right)$.

Laju pelindihan dilakukan menurut Japan Industrial Standard (JIS),yaitu laju pelindihan dipercepat dalam medium air. Polimer-limbah dalam bentuk 
silinder dengan diameter $25 \mathrm{~mm}$ dan tinggi $20 \mathrm{~mm}$ dimasukkan dalam basket dan dipasang pada alat soxhlet untuk direfluks dengan air bebas mineral pada suhu 100 0C selama 24 jam. Laju pelindihan dihitung berdasarkan Persamaan 5 .

$$
L=W / S . t
$$

dengan :

$\mathrm{L}=$ laju pelindihan $\left(\mathrm{g} \mathrm{cm}^{-2}\right.$ hari $\left.{ }^{-1}\right)$

$\mathrm{S}=$ luas permukaan contoh $\left(\mathrm{cm}^{2}\right)$

$\mathrm{W}=$ berat uranium dalam polimer-limbah yang terlindih $(\mathrm{g})$

$\mathrm{t}=$ waktu pelindihan (hari).

\section{HASIL DAN PEMBAHASAN}

Hasil penelitian penjerapan uranium oleh resin penukar anion disajikan pada Gambar 3 dan 4, sedangkan hasil pengukuran karakteristik polimer-limbah hasil solidifikasi disajikan pada Gambar 5 dan 6.

Pengaruh penambahan pengkompleks $\mathrm{Na}_{2} \mathrm{CO}_{3}$ terhadap besarnya uranium yang terserap disajikan pada Gambar 3.

Berdasarkan Gambar 3 tampak bahwa penjerapan uranium menurun dengan bertambahnya pengkompleks $\mathrm{Na}_{2} \mathrm{CO}_{3}$. Hasil penjerapan yang optimal diperoleh pada penambahan $\mathrm{Na}_{2} \mathrm{CO}_{3}$ sebanyak 0,75 gram dengan penjerapan uranium mencapai $88,5 \%$ berat, sehingga diperoleh perbandingan komposisi $\mathrm{U} / \mathrm{Na}_{2} \mathrm{CO}_{3}$ yang optimal adalah 0,067. Semakin besar $\mathrm{Na}_{2} \mathrm{CO}_{3}$ yang ditambahkan, maka penjerapan uranium akan menurun. Hal ini karena banyaknya ion $\mathrm{CO}_{3}^{-2}$ bebas dalam larutan, sehingga akan terserap oleh resin amberlit dan kapasitas serap resin untuk uranium menjadi berkurang. Sebaliknya jika $\mathrm{Na}_{2} \mathrm{CO}_{3}$ yang ditambahkan terlalu kecil maka uranium yang terbentuk menjadi $\left[\mathrm{UO}_{2}\left(\mathrm{CO}_{3}\right)_{3}\right]^{-4}$ sedikit, sehingga jumlah uranium yang terjerap resin amberlit juga sedikit.

Penelitian menggunakan perbandingan $\mathrm{U} / \mathrm{Na}_{2} \mathrm{CO}_{3}$ 0,067 dalam berbagai waktu kontak, diperoleh hasil percobaan seperti yang disajikan pada Gambar 4. 


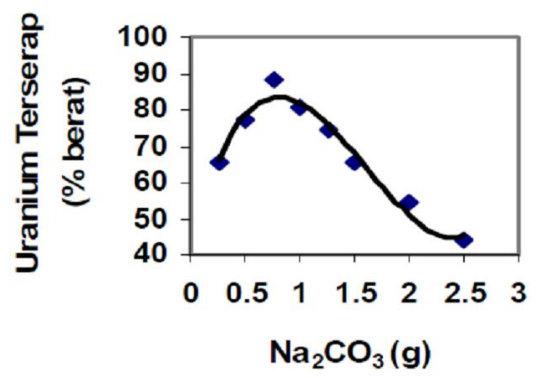

Gambar 3. Pengaruh Jumlah Pengkompleks $\mathrm{Na}_{2} \mathrm{CO}_{3}$ terhadap Penjerapan Uranium

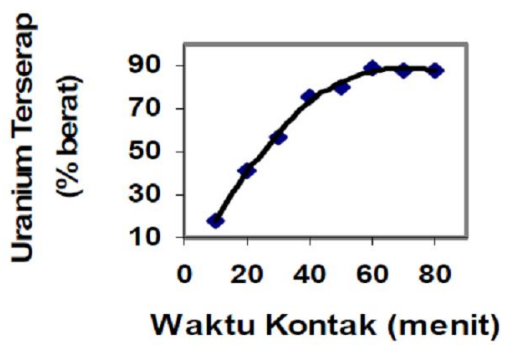

Gambar 4. Pengaruh Waktu Kontak terhadap Penjerapan Uranium

Berdasarkan Gambar 4 tampak bahwa dengan bertambahnya waktu kontak, maka jumlah uranium yang terserap semakin meningkat. Penjerapan jumlah uranium akan kembali stabil setelah waktu kontak 60 menit dengan jumlah penjerapan $88,6 \%$ berat, sehingga waktu kontak 60 menit inilah yang merupakan waktu kontak yang optimal.

Karakterisasi polimer-limbah hasil solidifikasi dimulai dengan pengamatan secara visual polimer-limbah hasil solidifikasi. Pada kandungan limbah $0 \%$ berat, maka polimer-limbah berwarna jernih kekuningan dengan sifat bahan yang kaku dan kuat. Pada kandungan limbah yang semakin besar, maka warna polimer-limbah akan semakin kecoklatan, hal ini karena adanya jumlah resin amberlit jenuh uranium yang semakin mendominasi warna polimer-limbah.

Hasil pengukuran densitas polimer-limbah hasil solidifikasi disajikan pada Gambar 5. Gambar 5 menunjukkan bahwa kandungan limbah yang semakin besar, maka densitas polimer limbah akan semakin meningkat. Hal ini karena semakin besar kandungan limbah maka semakin banyak atomatom uranium dengan berat atom yang tinggi yang terkandung dalam polimer limbah, sedangkan jumlah polimer semakin menurun. Struktur polimer sendiri tersusun dari atom-atom $\mathrm{C}$ dan $\mathrm{H}$ dengan berat atom yang lebih 
rendah, sehingga mengakibatkan densitas campuran polimer limbah hasil kondisioning menjadi semakin tinggi.

Karakteristik kuat tekan polimer-limbah hasil solidifikasi disajikan pada Gambar 6.

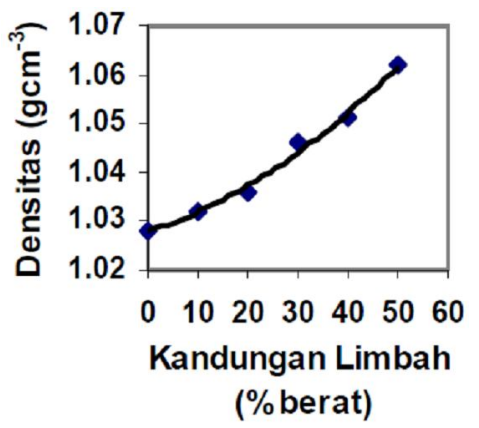

Gambar 5. Pengaruh Kandungan Limbah terhadap Densitas Polimer-Limbah

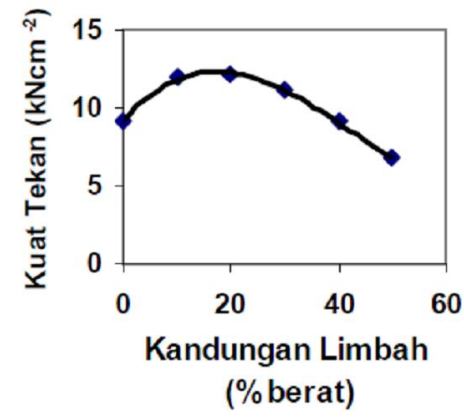

Gambar 6. Pengaruh Kandungan Limbah terhadap Kuat Tekan PolimerLimbah

Berdasarkan Gambar 6 tampak bahwa kuat tekan yang optimal diperoleh pada kandungan limbah $20 \%$ berat yaitu $12,153 \mathrm{kN} / \mathrm{cm}^{2}$. Semakin besar kandungan limbah, maka kuat tekan polimer-limbah akan semakin menurun. Hal ini disebabkan oleh kenaikan kandungan limbah akan diikuti dengan penurunan jumlah polimer resin epoksi yang digunakan. Semakin besar prosentase limbah, maka prosentase polimernya semakin sedikit. Ini berarti rantai polimer yang terbentuk semakin pendek. Dengan rantai polimer yang semakin pendek dan volume polimer-limbah yang semakin besar, maka tiap lapisan rantai polimer tidak cukup mengungkung limbah, sehingga kuat tekannya semakin menurun. Pengadukan yang kurang homogen pada saat pencampuran limbah dengan polimer dapat mengakibatkan penurunan kuat tekan. Hal ini disebabkan oleh banyaknya pori-pori sehingga polimer-limbah menjadi rapuh. 
Pengujian laju pelindihan yang dilakukan dengan alat sokhlet menunjukkan bahwa tidak nyata terdeteksi adanya uranium yang terlindih keluar dari polimer-limbah. Hal ini akibat uranium telah terikat cukup kuat oleh 2 bahan, yaitu resin amberlit dan polimer resin epoksi, sehingga uranium sulit terlindih keluar dari polimer-limbah. Berdasarkan pertimbangan densitas, kuat tekan, dan laju pelindihan yang mana dalam ketiga karakteristik tersebut telah termasuk pertimbangan keselamatan dan juga faktor ekonomi, maka polimer-limbah hasil solidifikasi terbaik diperoleh pada kandungan limbah $20 \%$ berat dengan densitas $1,036 \mathrm{~g} / \mathrm{cm}^{3}$, kuat tekan $12,153 \mathrm{kN} / \mathrm{cm}^{2}$ dan tidak nyata terdeteksi adanya uranium keluar dari polimer-limbah.

\section{KESIMPULAN}

Pengolahan limbah uranium dari produksi radioisotop dilakukan dengan penjerapan uranium oleh resin penukar anion. Percobaan penjerapan limbah simulasi yang mengandung uranium $0,05 \mathrm{~g} / \mathrm{L}$ dilakukan dengan resin penukar anion amberlit IRA-400 (Cl) menggunakan pengkompleks $\mathrm{Na}_{2} \mathrm{CO}_{3}$. Penjerapan uranium optimal diperoleh pada penambahan $\mathrm{Na} 2 \mathrm{CO} 3$ sebanyak 0,75 gram $\left(\mathrm{U} / \mathrm{Na}_{2} \mathrm{CO}_{3}=0,067\right)$, waktu kontak 60 menit dengan penjerapan uranium 88,6 \% berat. Karakteristik polimer-limbah hasil solidifikasi menunjukkan bahwa kandungan limbah yang optimal adalah $20 \%$ berat dengan densitas $1,036 \mathrm{~g} / \mathrm{cm}^{3}$, kuat tekan12,153 kN/ $/ \mathrm{cm}^{2}$ dan tidak terdeteksi adanya pelindihan uranium keluar dari polimer-limbah.

\section{DAFTAR PUSTAKA}

1. AWALUDIN,R., 2009, "Mencari Jejak Menggunakan Radioisotop", Terdapat: http://beritaiptek.istecs.org/mencari-jejak-menggunakan-radioisotop, diakses 22- 9-2009.

2. HERBANU, D.,A., 2004, "Produksi Radioisotop Mo-99 Hasil Fisi U-235", PT. BATEK, Serpong.

3. IAEA, 1995, "Alternative Technologies for ${ }^{99 \mathrm{~m}}$ Tc Generator" (Tecdoc No. 852), IAEA, Vienna.

4. IAEA, 1989, "Fission Molibdenum for Medical Use" (Tecdoc No. 515), Vienna.

5. DE VILLIERS, W. VAN ZYL., 1995, "The Production of Fission ${ }^{99}$ Mo and Management of The Resultant Waste" (IAEA- RTC on Management of Low Level Radioactive Waste from Hospital and Other Nuclear Applications), IAEA, South Africa. 
6. JNC, 2000, "Research and Development for the Geological Disposal of HLW in Japan" (Second Progress Report ), JNC, Japan.

7. ARAI T.; ABHARWAL K N., 2002, Nucl Sci Technol, 3 (Supplement) J882885.

8. MARS, S.,F.; JARVINEN, G.D,. BARTSCH R.,A.; NAM, J.; and BARR, M.,E, 1997, "J Reactive and Functional Polymers", 35 (1) 75-80.

9. JAMES E MARK , 2006, Physical Properties of Polymers Handbook, Springer.

10. MARCEL, R.; MIKHAIL R.; and WOLFGANG H., "J.Reactive and Functional Polymers", 68 (6) (2008) 1072-1080.

11. SAKR, K.; SAYED, M.,S,; HAFEZ, M.,.B., 2003, "Journal of Radioanalytical and Nuclear Chemistry",.256 (2) 179-184.

12. JOEL R. FRIED. 1995, Polymer Science and Technology, Prentice-Hall Inc.

13. IAEA, 1997, "Characterization of Radioactive Waste Form and Packages" (Technical Report Series No. 383), IAEA,Vienna.

14. IAEA, 2007, "Strategy and Methodology for Radioactive Waste Characterization" (Tecdoc No.1537), Vienna.

15. DAN CAMPHELL; RICHARD A. PETRICK; JUN R. WHITE, 2000, Polymer Characterization: Physical Techniques, Oxford University Press.

16. GEORGE, M.; CRANKOVIC, 1992, Materials Characterization, ASM International. 
